\title{
Business Cycle Implication of Exchange Rate-Based Stabilization
}

\author{
Hyuk Jae Rhee \\ Department of Economics, University of Windsor \\ Windsor, Ontario, N9B 3P4 Canada \\ Tel: 1-519-253-3000 (2385); Fax: 519-973-7096Ｅ-mail: jayrhee@uwindsor.ca
}

\begin{abstract}
The purpose of this study is to analyze the business cycle associated with the exchange rate-based inflation stabilization policy. We develop a stochastic dynamic general equilibrium small open economy model characterized by two sectors of economic activities (tradable and non-tradable), imperfect competition and sticky price in the non-tradable sector, a cash in advance constraint for consumption goods, and endogenous labour supply. The model is calibrated and solved numerically to examine the resulting equilibrium dynamics. Result shows that the model can replicate quantitatively the stylized facts of the credible exchange rate-based stabilization programs, the slow convergence of the inflation to the target rate and the sustained expansion of domestic sector. The model can also produce the "boom-recession cycle" and inflation persistence in the case of temporary stabilizations.
\end{abstract}

Keywords: Business Cycle, Exchange Rate, Inflation Stabilization

\section{Introduction}

Since World War II many Latin American countries have experienced high and persistent rate of inflation, which in some cases have lasted up to the present day. Such countries have engaged in repeated inflation stabilization efforts using the exchange rate as a nominal anchor. For example, in the late 1970s, the Southern-Cone countries such as Argentina, Chile, and Uruguay, fought inflation by implementing exchange-rate based stabilization programs. Unfortunately, most of these stabilization attempts have been unsuccessful in eliminating inflation except the recent stabilization programs of Argentina and Mexico, where policy makers successfully lowered the rate of inflation to the international level.

The common stylized fact of the exchange rate-based stabilization is that the rate of inflation converges slowly to the target rate whether the stabilization attempts are successful or not. The business cycle associated with stabilization programs has also attracted attention. In the failed stabilization attempts, domestic real economic activities, such as consumption and output, expanded in the early stage of program. Later even before the program was abandoned, consumption and output shrank and the trade balance went into deficit, thus, recession set in. This is called "boom-recession cycle" of exchange-based stabilization programs. In the successful stabilizations [Argentina (1991-1994) and Mexico (1988-1992)], however, the initial boom of domestic sector was not followed by a recession. During the stabilization, the labour participation rates rose and the domestic economic activities expanded with sustained real exchange rate appreciation. The trade balance and the current account balance improved during the stabilization.

A lot of theoretical researches have tried to explain these intriguing phenomena. Early works by Rodriguez (1982) and Dornbusch (1982) offered a simple description of the Southern-Cone exchange rate-based programs. They emphasized the presence of sticky inflation. Rodriguez assumes adaptive expectations to point out the backward-looking price and wage behaviour. Dornbusch assumes rational expectations and stickiness of inflation. These models conclude that inflation persistence and boom-recession cycle result from sticky inflation.

An alternative explanation to the major effects of stabilization is "temporariness hypothesis" by Calvo and Ve'gh $(1993,1994)$. This hypothesis considers the case in which inflation is flexible even if prices or wages are sticky due to forward-looking staggered pricing. Under these circumstances, they argued that slow convergence of inflation and "boom-recession cycle" arose from lack of credibility. Rapid convergence of inflation, therefore, can be achieved under the fully credible stabilization policy. Lahiri (2001) and Roldos (1997) studied the recent successful stabilization programs, such as Mexico's 1987 and Argentina's 1991 convertibility plan. In their studies, it was argued that inflation stabilization might have played an important role in unleashing supply-side responses in labour and investment, and induced sustained expansion of real economic activities observed in the successful stabilizations.

The purpose of this study is to analyze the business cycle associated with the exchange rate-based inflation stabilization policy. To this end, we develop a stochastic dynamic general equilibrium small open economy model characterized by two sectors of economic activities (tradable and non-tradable), imperfect competition 
and sticky price in the non-tradable sector, a cash in advance constraint for consumption goods, and endogenous labour supply.

In the model presented here, inflation acts as a tax on consumption goods and generates a wedge between the prices of consumption goods and leisure. This wedge causes individual labour supply to be a decreasing function of the rate of inflation. Therefore, lower rate of inflation by stabilization policy increases labour supply and generates expansion in non-tradable sector. However, inflation decreases slowly and shows significant persistence because of the sticky price of non-tradable goods. In this study, we introduce simple one-period, backward-looking wage contract model, which makes both rate of inflation and price of non-tradable goods sticky.

The model is calibrated and solved numerically to examine the resulting equilibrium dynamics. The results show that the model can replicate quantitatively the stylized facts of the successful exchange rate-based stabilization programs, inflation persistence, and sustained expansion of domestic economic activities, real appreciation, and improvement of current accounts. This result is consistent with the stylized facts of successful stabilization programs such as Argentina (1991-1994) and Mexico (1988-1992). For the temporary stabilization scenario, the model is also able to produce the "boom-recession cycle" and inflation persistence. These results are also consistent with the stylized facts of unsuccessful inflation stabilization attempts described in Calvo and Ve'gh (1993, 1994).

The distinguishing feature of this study, however, is that credible exchange rate-based disinflation produces a sustained expansion with slow inflation convergence. These results can be compared with those of Lahiri (2001) and Roldos (1997). These results also contrast with Calvo and Ve'gh's (1993, 1994) emphasis on forward-looking staggered pricing and demand-determined output. The key ingredients for reproducing the stylized facts of disinflation are a backward-looking wage setting and an endogenous labour supply.

The plan of this paper is as follows. We present the basic model and the equilibrium in Section II. The impact effects and transitional dynamics of credible and temporary disinflation policy are discussed in Section III. In Section IV, we draw the main conclusions.

\section{The model}

Consider a small open economy that is perfectly integrated with the rest of the world in goods and capital markets. This economy consists of households that supply labour, purchase goods for consumption, and hold money and internationally tradable bonds and firms that hire labour, and produce and sell differentiated non-tradable products in monopolistically competitive markets.

\subsection{Household}

The lifetime utility of the representative household is given by

$$
E_{t} \sum_{t=0}^{\infty} \beta^{t} u\left(C_{t+t^{2}}^{z} C_{t+t^{2}}^{*} b_{t+t}\right)
$$

where $C^{T}$ is the consumption of the tradable good and $C^{N}$ is a non-tradable consumption index, defined by

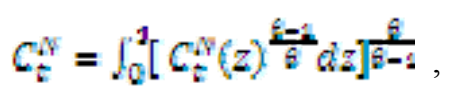

where $C^{N}(z)$ is the household's consumption of good $z ; \beta$ is the positive and constant subjective discount rate; and $\theta \geqslant 1$ is the elasticity of substitution between non-tradable goods. The last term in the lifetime utility function in Eq.(1) captures the utility from leisure. Normalizing the total available time for work and leisure to one, labour supply is given by

$N_{t}=1-l_{t}$

In order to obtain a closed form solution, we assume the following period utility function, which exhibits constant relative risk aversion:

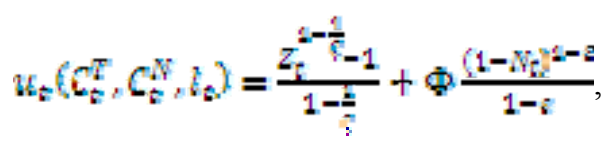

where $\xi \theta$ is the elasticity of intertemporal elasticity of substitution; $\theta$ is linked to the intertemporal elasticity of labour supply; $\Phi$ is a positive constant; and Z, an aggregate consumption, takes constant-elasticity-of substitution (CES) functional form: 
$z_{t}=\left(C_{t}^{T}\right)^{x}\left(C_{t}^{N}\right)^{1-\gamma}$

where $0 \leqslant \gamma \leqslant 1$. In this form, the intratemporal elasticity of substitution between tradable and non-tradable goods is given by 1 .

We employ the convention of letting 5 represent the nominal exchange rate in units of domestic currency per unit of foreign currency, while $P^{T}$ represents the domestic currency price of the tradable good. We assume that the law of one price holds for the tradable good. Therefore, the domestic currency price of the tradable good is $F^{T}=S P^{T}$ In this case, $F^{N}$ denotes the aggregate domestic currency price index of the non-tradable goods, defined as

$P_{t}^{N}=\int_{n}^{1}\left[P_{t}^{N}(z)^{1-\theta} d z\right]^{\frac{1}{1-6}}$

With CES aggregate consumption function, aggregate consumption price index is

$P_{t}=\frac{\left(P_{t}^{T}\right)^{\gamma}\left(P_{t}^{W}\right)^{1-\gamma}}{\gamma^{\gamma}(1-\gamma)^{1-\gamma}}$

The real exchange rate (the relative price of tradable goods in terms of non-tradable goods) can be defined as

$$
\varepsilon_{t}=\frac{E_{t}^{t}}{\theta_{t}^{t}}=\frac{\theta_{t} E_{t}^{*}}{E_{t}^{*}}
$$

For simplicity, we assume that $F^{v *}=1$ and is constant.

The representative household can hold two types of assets as their financial wealth: domestic non-interest bearing currency and an internationally tradable bond with a constant real interest rate (in terms of tradable goods). We also assume that the household has a constant endowment flow of tradable goods, $Y_{:}^{\bar{T}}$, while it derives human wealth from supplying labour to firm $z$ for the nominal wage $W_{\mathrm{r}}$. The households also owns firm $z$. Therefore, it can earn the profit of the firm, Г. Then the household's dynamic budget constraint is

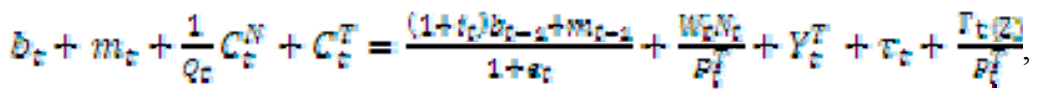

Where $\mathrm{b}, \mathrm{m}$, and $\tau$ are an internationally tradable bond, a domestic currency, and transfers from the government in terms of tradable goods, respectively; $i$ is the nominal interest rate; $\mathrm{W}$ is the money wage rate; $\boldsymbol{z}$ is the rate of depreciation defined by

$$
\epsilon_{t}=\frac{S_{t}-S_{i-1}}{S_{i=-1}}
$$

In this study, we only consider the fixed exchange rate regimes. Hence, $z$, is the rate of devaluation that is the exogenous policy process.

In order to carry out consumption expenditures, the household is required to hold sufficient domestic money. The

cash-in-advance constraint which the household faces is

$$
\left(\frac{C_{t}^{X}}{Q_{t}}+C_{t}^{T}\right) \leq \frac{m_{i-2}}{1+\tau_{t}}+\tau_{\tau}
$$

Eq. (7) implies that the minimum required money balances are proportional to the value of consumption expenditures. If the nominal interest rate is positive, the household will hold the minimum required money. Then the cash-in advance constraint (7) will be binding.

The household's optimization problem is to choose the path of $\sigma_{t}^{\gamma}, \sigma_{?}^{\gamma}$ and $N_{t}$ to maximize lifetime utility, (1), subject to initial wealth, an intertemporal budget constraint, and cash-in-advance constraint. The first order conditions are

$$
\begin{aligned}
& \frac{\gamma}{1-\gamma} \frac{\sigma^{y}}{d}=\mathrm{P}_{\mathrm{t}}, \\
& \Phi\left(1-N_{\theta}\right)^{-a}=\lambda_{2}=\frac{\omega}{f t},
\end{aligned}
$$




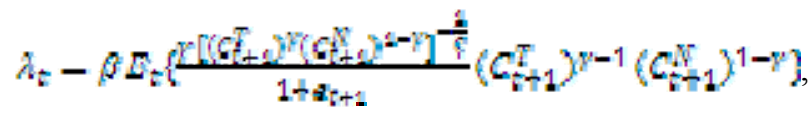

$$
\begin{aligned}
& \lambda_{t}=\beta E_{t}\left\{\left(\frac{1+t_{i}}{1+\pi_{t}}\right) \lambda_{i+1}\right),
\end{aligned}
$$

where $\lambda_{t}$ is the Lagrange multiplier associated with the household's dynamic budget constraint (5). As usual, it can be interpreted as the marginal utility of wealth. Equation (8) indicates that at an optimum, the household equates the marginal rate of substitution between tradable and non-tradable goods to the relative price of tradable goods in terms of non-tradable goods which is the real exchange rate. Equation (9) is the Euler equation for optimal labour supply. It ensures that the marginal disutility of labour (due to forgone leisure) equals the marginal utility of real wage. Equation (11) is a standard asset pricing equation.

\subsection{Government}

The other participant in this economy is the government. In this study, we assume that the government runs a balanced budget in every period. We also assume that the government returns to the consumer all of its seignorage revenues in the form of transfers:

$$
0=\frac{B S_{i}-B_{i-1}}{P^{T}} \text {. }
$$

We also need to specify the process followed by the nominal stock of money. Let $v$ be the growth rate of nominal money supply. Then money creation process is given by

$$
M_{i}=\left\langle 1+y_{t}\right) M_{t-1} \text {. }
$$

Then the real money balance in terms of tradable goods is

$$
m_{t}=\left(\frac{1+v_{i}}{1+a_{i}}\right) m_{t-1}
$$

To avoid unnecessary balance of payments disequilibrium, we assume that the government sets the growth rate of nominal money supply equal to the rate of devaluation $(v=z)$. Then equation (14) implies

$$
m_{t}=m_{t-1} \text {. }
$$

It also implies that the government chooses the transfer $(\tau)$ to compensate for the depreciation cost of holding money as

$$
\tau_{t}=\left(\frac{q_{i}}{1+\varepsilon_{t}}\right) m_{t}
$$

\subsection{Supply side and inflation dynamics}

We now turn to the supply side of the economy. For simplicity, we assume that the supply of tradable goods is exogenous and fixed at the constant level $Y^{T}$ (i.e., $Y_{\tau}^{\tau}=Y^{T}$ for all $t$ ) and its domestic price will be determined by the law of one price, while the non-tradable good sector operates under imperfect competition and sticky price.

There is a continuum of imperfectly competitive firms indexed by $z$ in $[0,1]$. Each producer produces a differentiated good and acts as a monopolistic competitor, choosing the nominal price and the level of production of the good.

Given the CES non-tradable consumption index, Eq.(2), an individual's demand for non-tradable good $z$ in period $t$ is

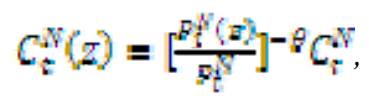

where $\theta$ is the price elasticity of demand, and $C_{v}^{N}=\int_{0}^{1} C_{v}^{N}(z) d z$ is aggregate per capita non-tradable good consumption.

According to Eq.(17), a monopolistically competitive firm that produces a non-tradable good faces the downward-sloping demand curve

$$
Y_{t}^{N}(z)=\left[\frac{B^{N}(z)}{\theta_{t}^{N}}\right]^{-\theta} C_{t}^{N}
$$


Labour is the only input into production. The technology available to firms is identical and is linear in labour:

$$
y_{t}^{N}(z)=N_{t}(z) \text {. }
$$

Firm Z's profit is

$$
F_{t}^{N}(z) \psi_{t}^{d}(z)-W_{t} N_{t}
$$

At any time $t$, a monopolistically competitive firm maximizes profit, Eq.(20), subject to the demand function, Eq.(18), and the production function, Eq.(19). Solving the firm's problem:

$$
P_{t}^{N}(z)=\frac{\theta}{\theta-1} W_{t} \text {. }
$$

Equation (21) shows that a producer with market power sets prices above marginal cost (the money wage rate), which is the standard pricing condition of the imperfectly competitive market.

We now introduce the assumption that the price of non-tradable good is sticky because of nominal wage rigidity. It is assumed that nominal wages are set for one period in advance with all wage contracts negotiated every period. It would be more appropriate to assume the multiple periods staggered wage contacts. The multiple periods staggered contact model will enrich the inflation dynamic of the model at the cost of grater complexity. Thus, in this study, we consider only single-period synchronized wage contract model. Let $W_{t}$ be the log of contracted nominal wage, set in period $t$. Then

$$
w_{t}=p_{t-1}+k y_{t}^{N} \text {, }
$$

where $p_{t-1}$ is the log of aggregate price index at time $t-1 ; \gamma_{t}^{N}$ is the log of non-tradable output at time $t$; and $0 \leq k \leq 1$ reflects sensitivity of contract wage to the current condition in non-tradable sector. Eq.(22) indicates that agents care about relative wages in terms of aggregate price index, and it also implies that a wage setting is a backward-looking indexation. Agents index a current nominal wage to the past aggregate price level. The contract wage is also assumed to be increasing in the level of non-tradable output.

With non-tradable price assumed to be a constant mark-up over wage costs, log of non-tradable price is given by

$$
p_{t}^{N}=\log \frac{\theta}{\theta-1}+p_{t-1}+k y_{t}^{N} \text {. }
$$

Equation (23) implies that any change in the aggregate price level translate into the non-tradable price with one-period lag through the nominal wage rate. Since the aggregate price index includes the price of tradable goods, the non-tradable price will vary with the tradable price.

From the aggregate price index, we can obtain

$$
P_{t}=\alpha+\gamma P_{\tau}^{T}+(1-\gamma) P_{\tau}^{N}
$$

where $p$; and $p^{T}$ are log of aggregate price index and $\log$ of tradable price, respectively, and $\alpha$ is a constant. Substitute (23) into (24) and normalize constant give us

$$
p_{t}=\gamma s_{t}+(1-\gamma) p_{t-1}+k(1-\gamma) y_{t}^{N},
$$

where $s_{t}$ is a log of nominal exchange rate. From (25), we can see that the aggregate price level will fluctuate with nominal exchange rate. For example, nominal appreciation (or revaluation), lowers the aggregate price level by reducing the domestic currency price of foreign goods as well as reducing the nominal wage rate. Through these two channels, exchange rate disturbance can have an impact on the aggregate price level. From (25), we are able to obtain the aggregate inflation dynamic

$$
\pi_{t}=\gamma \varepsilon_{t}+(1-\gamma) \pi_{t-1}+k(1-\gamma)\left[y_{t}^{N}-y_{t-1}^{N}\right] .
$$

\subsection{Equilibrium and Steady-state}

In equilibrium, all monopolistic non-tradable producers behave identically to each other in the sense that they produce same level of non-tradable output and charge the same price. Thus symmetric equilibrium is characterized by the following conditions

$$
\begin{aligned}
& P_{t}^{N}(z)=P_{t}^{N}, \forall z, \\
& Y_{t}^{N}(z)=Y_{t}^{N}, \forall z, \\
& N_{t}^{N}(z)=N_{t}, \forall z,
\end{aligned}
$$


and

$$
Y_{i}^{*}=C_{i}^{W} \text {. }
$$

Equation (27) is a non-tradable goods market equilibrium condition. Making use of the non-tradable goods market equilibrium condition and of government budget constraint we can write equation (5) as

$$
b_{i}=\left(1+i_{s}\right)\left(1-\epsilon_{i}^{3-1} b_{i}+Y^{T}-C_{t}^{T},\right.
$$

where $Y^{T}$ is a constant level of tradable output. Equation (28) represents the current account or trade balance equation. Combining (10) and (21) gives labour market equilibrium condition as

$$
\Phi\left(1-N_{6}\right)^{-z}=\left[\frac{\theta-1}{\theta}\right] \lambda_{6} \theta_{z}^{-1}
$$

The binding CIA constraint with the government transfer gives the equilibrium money demand

$$
\frac{1}{Q_{t}} C_{t}^{N}+C_{t}^{T}=m_{t}
$$

which determines money market equilibrium together with equation (15).

Suppose that, prior to any stabilization, the devaluation rate is $\varepsilon_{z z}$ and is expected to remain at that level forever. For a given steady state level of devaluation rate, the economy at a steady state is characterized by

$$
\begin{aligned}
& 1+t_{g g}=\left(1+r^{2}\right)\left(1+e_{g}\right) \text {, } \\
& \beta=\frac{1}{1+r^{*}} \text {, } \\
& \pi_{g g}=\epsilon_{g g},
\end{aligned}
$$

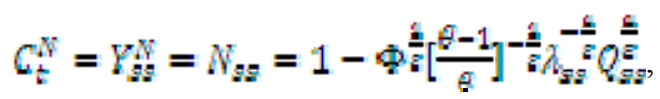

$$
\begin{aligned}
& C_{g y}^{T}=Y^{T}+\left(1+r^{*}\right) b_{g z} \\
& Q_{g g}=\left(\frac{\gamma}{1-\gamma}\right) \frac{c \|}{C_{s}} \text {. }
\end{aligned}
$$

At a steady state, consumption of tradable goods is equal to its permanent income level, while consumption of non-tradable equals its full-employment level. The full employment level of non-tradable is less than the socially efficient level because of the imperfection in the non-tradable sector. However, this full-employment level of output is not constant. Equation (10) implies that the Lagrange multiplier depends on the rate of devaluation. Therefore, any change in rate of devaluation at the steady state will affect the steady state level of Lagrange multiplier, which affects the level of non-tradable output in the long run. Nominal variables (the interest rate and the rate of inflation) are growing at the devaluation rate $\epsilon_{z z}$. T he real exchange rate is equal to the ratio of the steady state consumption of non-tradable to tradable.

\subsection{Log-Linearization}

Next, we need to linearize the model in terms of percentage deviations around steady state. The step involved in obtaining the linear approximation around steady state follows the approach of Campbell (1994) and Uhlig (1999). The resulting linearized system consists of the following equations:

$$
\begin{aligned}
& y_{*}^{N}=e_{*}^{N} \text {, } \\
& g\left(\frac{N_{s z}}{i n}\right) n_{t}=\hat{\lambda}_{t}-\hat{q}_{t} \\
& \hat{b}_{t}=\left(1+\hat{i}_{S S}\right)\left(1+\epsilon_{S S}\right)^{-1}\left[\hat{b}_{t-1}-\hat{s}_{t}+\hat{i}_{t-1}\right]-\frac{d S_{S}}{i_{S S} T}, \\
& \hat{A}_{t}=E_{t}\left[\hat{b}_{t+1}-\hat{s}_{t+1}+\hat{q}_{t+1}\right] \text {, } \\
& \xi_{\tau}-\xi_{\tau}^{T}=\xi_{t}, \\
& \hat{\lambda}_{t}=E_{t}\left[\left(1-\gamma+\frac{\gamma-1}{\zeta}\right) \varepsilon_{t+1}^{N}-\left(1-\gamma+\frac{\gamma}{\zeta}\right) \varepsilon_{t+1}^{T}-\varepsilon_{t+1}\right] \text {, }
\end{aligned}
$$




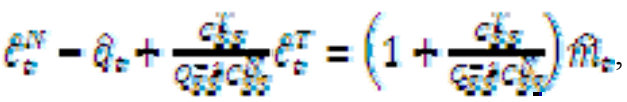

$$
\begin{aligned}
& \hat{A}_{t}=m_{t-1} \text {, } \\
& q_{t}=s_{t}-R_{t}^{N} \text {, } \\
& i_{t}=\varepsilon_{c+1} \text {, }
\end{aligned}
$$

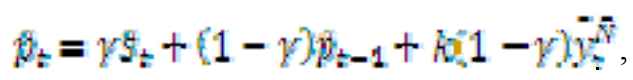

where $\hat{x}$ presents percentage deviation of a variable $\mathrm{X}$ around its steady state value. Equation (32) is the economy's non-tradable production function in which non-tradable output deviations from the steady-state are a linear function of the percentage deviations of the labour from the steady state. Equations (33) and (34) are non-tradable goods market and labour market equilibrium conditions. Equation (35) is the current account dynamics derived from the economy's resource constraint. Equations (36)-(39) are derived from the representative household's first-order conditions for consumption for tradable and non-tradable, leisure, and money holdings. Equation (40) is the money supply process derived from (17). The equations (41) and (42) represent real exchange rate and interest rate parity conditions, respectively. Equation (43) represents deviation of the price index from its steady state value.

To complete the model, we need to specify the process followed by the rate of devaluation. We let $\mu_{t} \equiv \epsilon_{t}-\epsilon_{S S}$ denote the deviation in period $t$ of the rate of devaluation from its steady state value. This deviation will be treated as a stochastic process given by

$$
\mu_{t}=\phi_{t-1}+\eta_{t}, 0<\Phi \underline{\leq} 1,
$$

where $\eta$ is a white noise process. This formulation allows the devaluation rate to display persistence and to be subject to random disturbance through the realization of $\eta$. The parameter $\phi$ represents the degree of persistence in the devaluation rate process. If $\phi=1$, then the realization of $\eta$ changes the rate of devaluation permanently. If $\phi<1$, however, it has only a temporary effect on the rate of devaluation.

If we assume that at the initial steady state, the devaluation is $\varepsilon_{55}$, then the rate of devaluation process is given by

$$
\varepsilon_{t}=\phi \varepsilon_{t-1}+\eta_{t}, 0 \leq \phi \leq 1 .
$$

A negative shock to rate of devaluation $\left(\eta_{t}<0\right.$ ), for example, now lowers the rate of devaluation permanently if $\phi=1$. However, it lowers the rate of devaluation temporarily if $\phi<1$.

Equations (32)-(43) with the rate of devaluation process (45) constitute a linearized version of the model. These equations represent a linear system of difference equations involving expectational variables. This linear rational

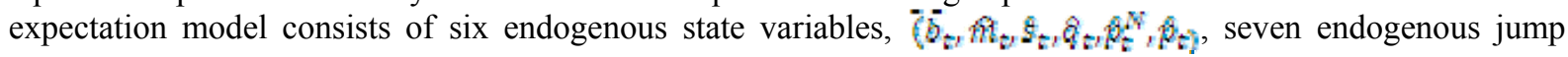
variables, $\left(\varepsilon_{t}^{T}, \varepsilon_{t}^{N}, n_{t}, y_{t}^{N}, \hat{\lambda}_{t}, \hat{A}_{t}^{N}, \hat{n}_{t}\right)$, and one exogenous state variable, $\epsilon_{t}$.

\subsection{State-space form and solution}

It is shown in Uhlig (1999) that model can be written in a convenient state-space form. Let $X_{t}$ and $y_{t}$ denote the (column) vector of endogenous state (backward looking) variables and endogenous jump (forward looking) variables, respectively, and let $Z_{z}$ denote exogenous state variable,

$X_{t}=\left[\hat{b}_{t} m_{t} \xi_{t} \hat{q}_{t} \theta_{t} \hat{p}_{t}\right]^{c}$

$Y_{t}=\left[\varepsilon_{t}^{T} \varepsilon_{t}^{N} n_{t} f_{t}^{N} \hat{\lambda}_{t} A_{t}^{N} A_{t}\right]^{\prime}$

$z_{t}=\left[\epsilon_{t}\right]$

Then model can be written

$$
\begin{aligned}
& 0=A X_{t}+B X_{t-1}+C Y_{t}+D Z_{t}, \\
& 0=E_{t}\left[E X_{t+1}+G X_{t}+H X_{t-1}+J Y_{t+1}+K Y_{t}+L Z_{t+1}+M Z_{t}\right], \\
& Z_{t+1}=N Z_{t}+\eta_{t},
\end{aligned}
$$


where

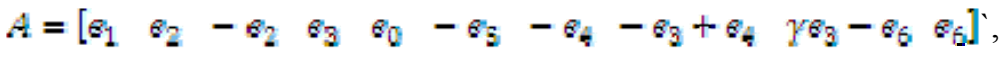

$$
\begin{aligned}
& B=\left[\begin{array}{llllllllll}
B_{1} & -\theta_{2} & \theta_{0} & -\theta_{2} & \theta_{0} & \theta_{0} & \theta_{0} & \theta_{0} & \theta_{0} & \theta_{6}
\end{array}\right]^{\prime \prime}, \\
& C=\left[\begin{array}{llllllllll}
\varepsilon_{1} & \theta_{0} & \theta_{1} & \theta_{0} & -\theta_{2}+\theta_{3} & \theta_{3} & -\theta_{4} & \theta_{8} & (1-\gamma) \varphi_{0} & -\theta_{6}
\end{array}\right]^{\prime}, \\
& D=\left[\begin{array}{llllllllll}
0 & 0 & 0 & -1 & 0 & 0 & 0 & 0 & 0 & 0
\end{array}\right],
\end{aligned}
$$

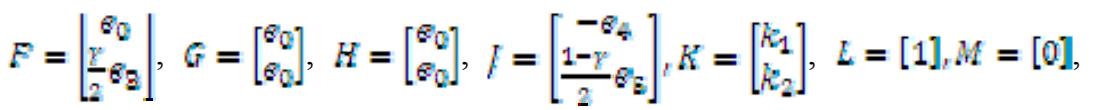

and

$b_{1}=-\left(1+\gamma^{*}\right) e_{1}$,

$c_{1}=\frac{d_{g}}{b_{g S}} e_{1}$,

$k_{1}=-\left(1-\gamma+\frac{\gamma}{q}\right) e_{1}+\left(1-\gamma+\frac{1-\gamma}{z}\right) e_{2}$,

$k_{2}=k \epsilon_{2}-\left(1+\frac{1-\gamma}{2}\right) \theta_{\mathrm{g}}$,

where $\varepsilon_{j}, t=0_{r \ldots \ldots} n_{i}$ denotes a $1 \times n$ row vector, for $t=0$ with all elements equal to zero, for $l \neq 0$ with element $j$ equal to unity and all other elements equal to zero.

Then the solution to the system takes the form of the stable recursive law of motion

$X_{t}=P X_{t-1}+Q \varepsilon_{t}$,

$Y_{t}=F X_{t}+S \varepsilon_{t}$

where $F$ and $R$ are $6 \times 6$ matrices, and $Q$ and 5 are $6 \times 1$ column vectors. Since all variables in $X_{5}, \gamma_{5}$, and $Z_{\mathrm{f}}$ are log-deviations, the entries in $F, Q, R, S$ and $N$ can be understood as elasticises and interpreted accordingly.

In the next section, we will use the recursive equilibrium law of motion to calculate impulse response of the model to a policy shock (devaluation shock).

\section{Exchange rate-based stabilization}

In this section, we study the effects of the exchange rate-based stabilization by simulating the response of the model to a permanent and a temporary stabilization plan. The simulation was carried out in the following way. First, we assign the values to the specific parameters. Second we set the pre-stabilization steady state and compute the dynamics of the model as it converges from the pre-stabilization steady state to the post-stabilization steady state.

We compute the impulse responses of the main economic variable to $1 \%$ devaluation shock. For the simulation purpose, we use the rate of revaluation instead of devaluation rate as our policy variable. Since the rate of devaluation is zero at the initial steady state, the reduction of rate of devaluation is equal to the increase in the rate of revaluation. The approach used to solve and to simulate the model follows Uhlig (1999).

\subsection{Model parameterizations}

We follow the open economy macro literature in picking parameter values for our policy experiments. In this version of the paper, we no not attempt to calibrate or estimate the model. The parameters are simply selected to be not unreasonable. Therefore, the numerical results are only indicative. First, we employ the points estimates of the elasticity of intertemporal substitution obtained by Reinhart and Ve'gh (1995) for Argentina $(\xi=0.2)$. We also follow Uribe (1997) in setting the parameter of the aggregate consumption function, $\gamma$, at 0.36 , which is consistent with the observed average share of tradables in GDP of $42 \%$ and with the average trade balance to GDP ratio of $2.6 \%$. This also implies that the steady state ratio of tradable consumption to the current account, $\frac{\sigma_{52}}{\sigma_{22}}$, will be 16 . We also assume that intertemporal elasticity of labor supply, $\varepsilon$, is equal to one with $\mathbb{V}_{S \Sigma}=\frac{1}{\mathbb{8}}$ as in Cooley and Prescott (1995). World real interest rate $r^{*}$ is set as $1 \%$ as in Rebelo and Ve'gh (1995). We also 
set the standard deviation of rate of depreciation, $\sigma_{z}$, as 0.75 and,$k$ the sensitivity of contract wage to the current condition in non-tradable sector, equal to 1 in the result we report.

\subsection{Credible Stabilization}

Consider the impact of once-and-for-all reduction in the rate of devaluation. This corresponds to the credible stabilization case in which the government lowers the rate of devaluation permanently. In this simulation, we use the rate of revaluation instead of devaluation rate as our policy variable. Therefore, the government increases the rate of revaluation permanently. In Figure 3, panel A displays the predicted dynamic of the rate of revaluation in response to a shock with $\phi=1$. The figure shows that the rate of revaluation remains at higher level for almost eight years after a shock, which is consistent with a permanent stabilization scenario.

Figure 1 shows the effect of revaluation shock on the rate of inflation. Inflation falls on impact and converges to the new steady state level. The initial fall of inflation rate is mainly due to the effect of revaluation shock on the tradable inflation. The increase in the rate of revaluation immediately reduces the tradable inflation through PPP. The non-tradable inflation, however, is sticky due to the backward-looking indexation of wage contracts. Therefore, the rate of inflation shows a substantial persistence during the transition to the new steady state. This is due to the backward-looking indexation of wage contracts. In this simulation, the rate of inflation exhibited considerable persistence even if the disinflation program is fully credible. This result is broadly consistent with the scenario of inflation persistence described by Rodriguez (1982), Dornbusch (1982), and Calvo and Ve'gh (1994).

The non-tradable output jumps on impact and increases to the new steady state level. The effect of revaluation shock on the non-tradable output is illustrated in Figure 2. According to interest rate parity condition, on impact, the nominal interest rate falls by the same amount as the rate of revaluation. The reduction in the nominal interest rate constitutes reduction in the monetary wedge generated by the cash-in-advance constraint. This increases labour supply of the household, which induces output expansion in non-tradable sector. Hence, by the market-clearing condition of non-tradable goods, consumption also increases. Since the greater labour supply implies more labour income, the consumer will increase demand for non-tradable. This permanent increase in labour supply triggers a positive wealth effect. Therefore, the supply-side effect of disinflation enters through the change in the labour supply.

In Figure 3, panel D we can see that labour supply increases to the new steady state level after the stabilization. In this simulation, the economy experiences a sustained expansion in domestic sector; non-tradable output (and consumption) expands up to the new steady state after the initial boom. This is a consistent result based on the evidence of the successful stabilizations with a high degree of credibility in Mexico (1988-1992) and Argentina (1991-1994) [See Roldos (1997)]. The distinguishing feature of this model compared to the previous one is that inflation stabilization attempt produces a sustained expansion even if inflation shows persistence. The dynamic adjustment of the other main variables is illustrated in Figure 2. The predicted dynamics of real exchange rate during adjustment is also consistent with what we observed in the recent successful stabilizations. Due to the sticky inflation, the rate of inflation remains above the nominal devaluation rate for some time. Therefore, the real exchange rate appreciates which is one of the main stylized facts in exchange-rate based stabilization. The path of the real exchange rate is illustrated in Figure 3, panel C. In this model, real appreciation co-exists with the expansion of domestic sector. During the adjustment to the new steady state the current account balance improves sharply, reflecting a large decrease in consumption of tradable goods. It should be noted that in this model, inflation stabilization proves to be welfare-improving: the reducing inflation is beneficial in cash-in-advance model with labour-leisure choice and imperfection in goods market. The lower inflation reduces the transaction cost. Hence it allows the individuals more free time for the productive activities, such as more consumption and production. In a broad sense, disinflation is welfare improving since the socially unproductive efforts to conserve on money balance can be eliminated.

\subsection{Temporary stabilization}

Now consider the implication of a temporary stabilization attempts. This corresponds to the case of lack of credibility: the authority announces a permanent reduction in the rate of devaluation, but the public believes that the rate of devaluation will go back to its original level after a certain period of time. This case corresponds to $\phi \leqslant 1$ in equation (45). For the simulation purpose, we also use the rate of revaluation instead of devaluation as our policy variable. In this study, we simulate the model with $\phi=0.25,0.5$, and 0.75 . However, simulation results are similar. Hence we illustrate the simulation result with $\phi=0.5$. The simulation results with $\phi=0.25$ and 0.75 are also illustrated in Figure 7 and Figure 8. The dynamic of the rate of revaluation in response to a shock with $\phi=0.5$ is depicted in Figure 6, panel A. The figure shows that the revaluation rate goes 
back to the original level in two years after the shock, which is also quite consistent with the temporary stabilization scenario.

First, we examine the behaviour of the non-tradable output. On impact the non-tradable output jumps and then starts to decrease, goes back to the pre-stabilization level. On impact, the nominal interest rate falls by the same amount as the rate of revaluation. The reduction in the nominal interest rate increases labour supply of the household, which induces output expansion in non-tradable sector in the early stage of stabilization. However, the revaluation as well as interest rate goes back to the original level after the policy is reversed. As the nominal interest rate goes back to the original level, the households decrease their labour supply. Thus, non-tradable output (or consumption) also shrinks and the recession sets in. This business cycle is consistent with the stylized fact of "boom-recession cycle" of Southern-Cone exchange rate-based stabilization in which consumption and output of domestic sector expand at the beginning of the programs and shrink later. Figure 4 shows the effect of revaluation shock on the non-tradable output. Inflation also falls on impact. However, the size of the initial jump of inflation will be smaller than the permanent case. After the initial impact, inflation starts to increase and returns to its initial steady state level. During the transition, inflation also shows a substantial persistence. This result is also consistent with the previous literature [Calvo and $V \backslash^{\prime}$ egh $(1993,1994)$ ]. Figure 5 shows the effect of revaluation shock on the rate of inflation.

The dynamic path of the other main variables is depicted in Figure 6. First, we observe the real appreciation followed by later depreciation. Another interesting feature of adjustment to the new steady state is a dynamics of the current account (Figure 6, panel F). During the transition, tradable consumption shrinks and the current account improves even if the stabilization policy is temporary. This result stands as sharp contrast with the stylized fact we observed in failed stabilization attempts in which the trade balance and current account balance deteriorate during the transition. This result, of course, is based on the assumptions of the constant-elasticity-of-substitution (CES) preferences and exogenous tradable output. If we introduce the endogenous tradable output supply, the result will be different.

\section{Concluding remarks}

This paper presents a stochastic dynamic general equilibrium small open economy model to explain the main stylized facts of the exchange rate-based stabilization programs. We extend a standard new open economy macroeconomic model to allow for sticky inflation by introducing the simple, one-period, backward-looking wage contract model. We also incorporate cash-in-advance constraint with endogenous labour supply. Inflation is modeled as a tax on consumption goods and generates a wedge between the price of consumption goods and the price of leisure. The model is calibrated and solved numerically to examine the resulting equilibrium dynamics. The model predicts the typical business cycle associated with the credible exchange rate-based stabilization program: the sustained expansion of real economic activities, persistent inflation, real appreciation, and the increase in labour supply. Therefore, the model is able to explain a number of features associated with the credible exchange rate-based stabilization program. It has also shown that the model is able to replicate the "boom-recession Cycle" and inflation persistence associated with a temporary stabilization attempt.

The analysis also shows that inflation persistence is mainly due to backward-looking indexation. As illustrated in the main text, stabilization, even if it is fully credible, is always accompanied by inflation persistence. Therefore, the inflation persistence during the program does not necessarily mean the possibility of failure if the backward-looking indexation in price or wage setting exists.

We also find that the credible exchange rate-based stabilization is welfare enhancing since a permanent reduction in the inflation rate reduces the distortion in domestic resources allocation between consumption and leisure. Therefore, as long as the policy maker continues to pursue this goal, they can reduce inflation without any output cost and, thus, enhance welfare.

\section{References}

Calvo,G.A., and C.A. Ve'gh. (1993). Exchange rate- based stabilization under imperfect credibility. in: H. Frisch and A. Worgotter (eds.), Open-Economy Macroeconomics, MacMillan Press, 3-28.

Calvo,G.A., and C.A. Ve'gh. (1994). Credibility and the dynamics of stabilization policy: a basic framework, In Sims, C.A.(Ed.). Advances in Econometrics: Sixth World Congress, Vol.2, Cambridge University Press, $377-420$.

Campbell, J.Y. (1994). Inspecting the mechanism: an analytical approach to the stochastic growth model, Journal of Monetary Economics 33: 463-506. 
Cooley, T.F., and E. Prescott. (1995). Economic growth and business cycle model, In T. F. Cooley (Ed.), Frontiers of Business Cycle Research, Princeton University Press, 1-38.

Dornbusch, R. \{(1982)\}, Stabilization policies in developing countries: what have we learned? World Development 10: 701-708.

Lahiri, A. (2001). Eachange rate based stabilizations under real frictions: The role of endogenous labor supply, Journal of Economic Dynamics and Control 25: 1157-1177.

Rebero, S. and C.A. Ve'gh. (1995). Real effects of exchange rate based stabilization: an anaysis of competing Theories, in: B.S. Bernanke and J.J. Rotemberg, eds., NBER Macoeconomics Annual, MIT Press, 125-174.

Reinhart, C.M., and C.A. Ve'gh . (1995). Nominal interest rates, consumption booms, and lack of credibility: quantitative examination, Journal of Development of Economics 46: 357-378.

Rodriguez, C.A. (1982). The Argentine stabilization plan of December 20th," World Development 10: 801-811.

Roldos, $\sim$ J. (1997). On gradual disinflation, the real exchange rate, and the current account, Journal of International Money and Finance 16: 37-54.

Uhlig, H. (1999). A toolkit for analyzing nonlinear dynamic stochastic model easily," in: R. Marimon and A. Scott (eds.), Computational Methods for the Study of Dynamic Economies, Princeton University Press, 30-61.

Uribe, M. (1997). Exchange rate based inflation stabilization: the initial real effects of credible plans, Journal of Monetary Economics 39: 197-221.

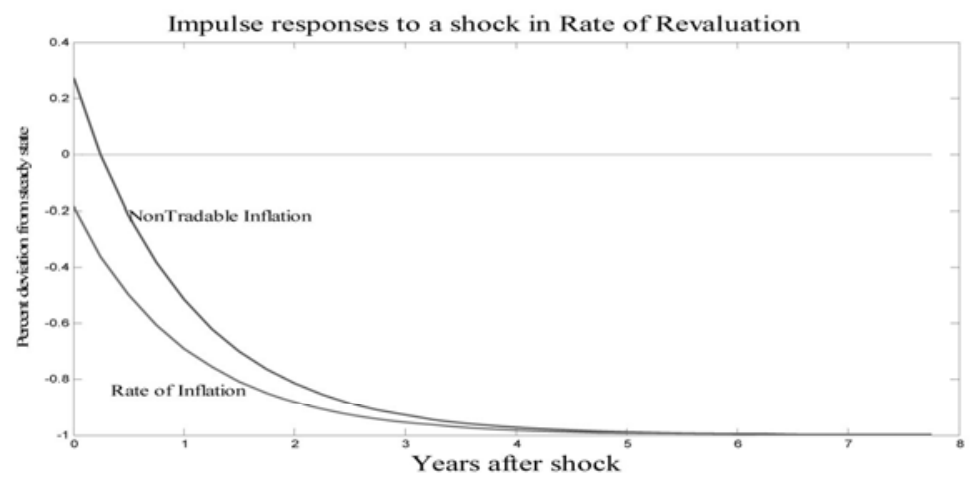

A: Response of the rate of inflation

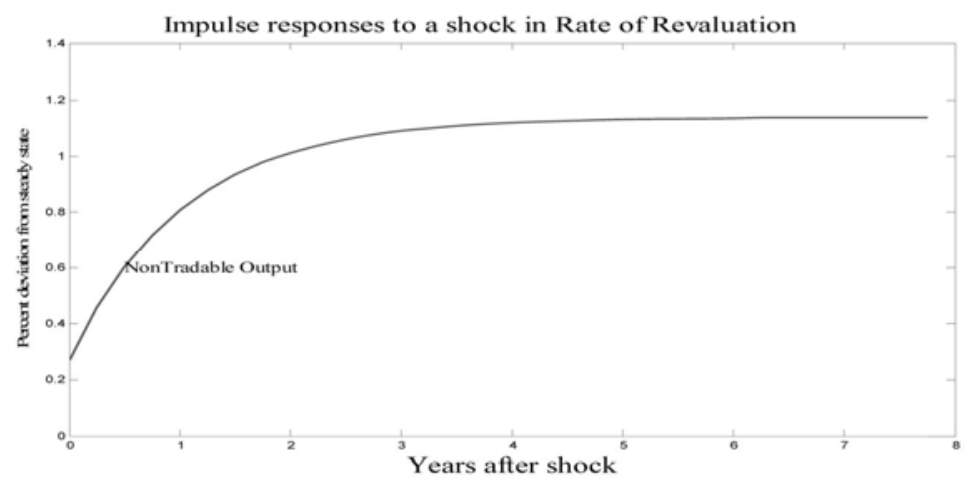

B: Response of Non-tradable output

Figure 1. Credible Stabilization: Response of the rate of inflation and Non-tradable output 

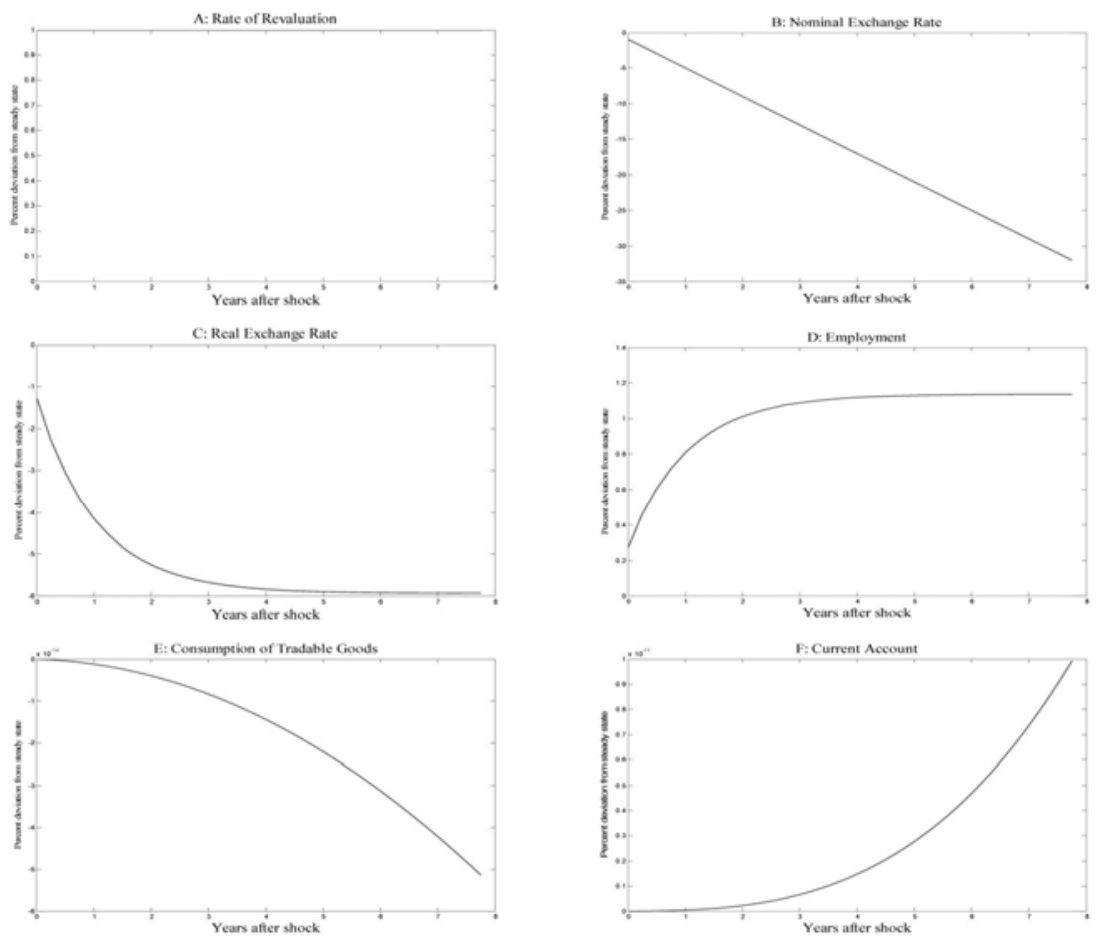

Figure 2. Credible Stabilization: Response other variables

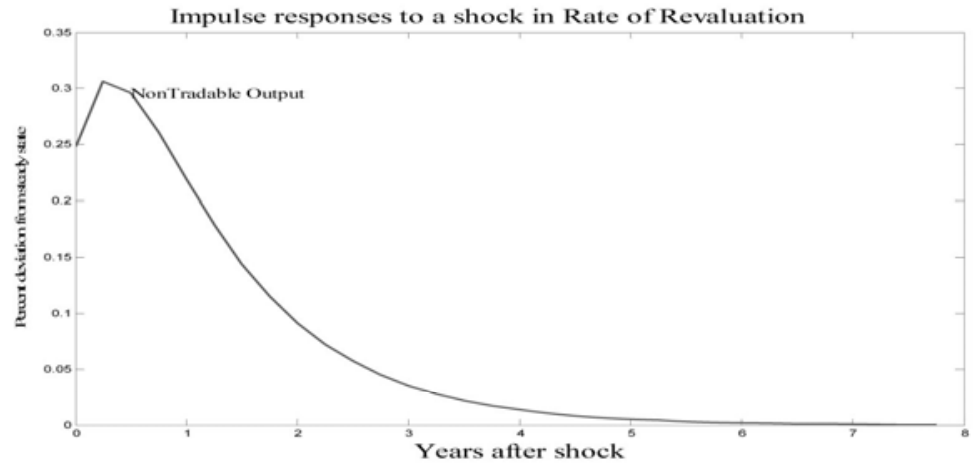

A: Response of the rate of inflation

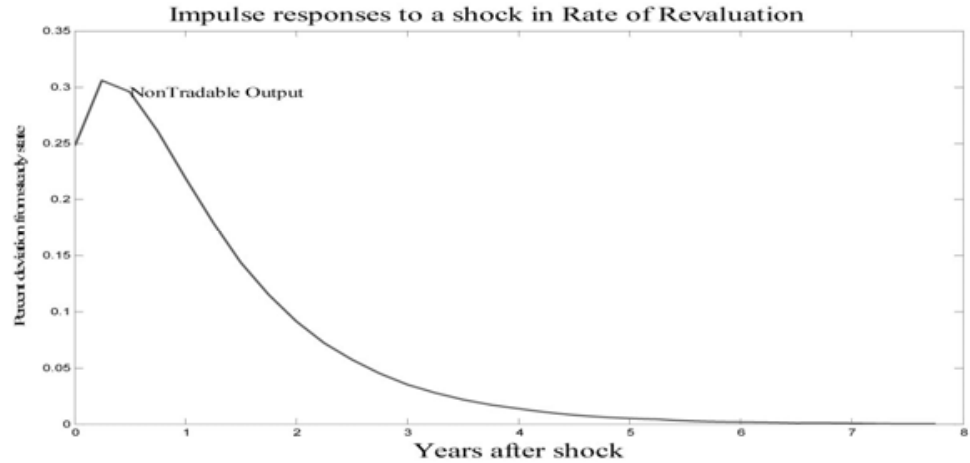

B: Response of Non-tradable output

Figure 3. Temporary stabilization: the rate of inflation and Non-tradable output 

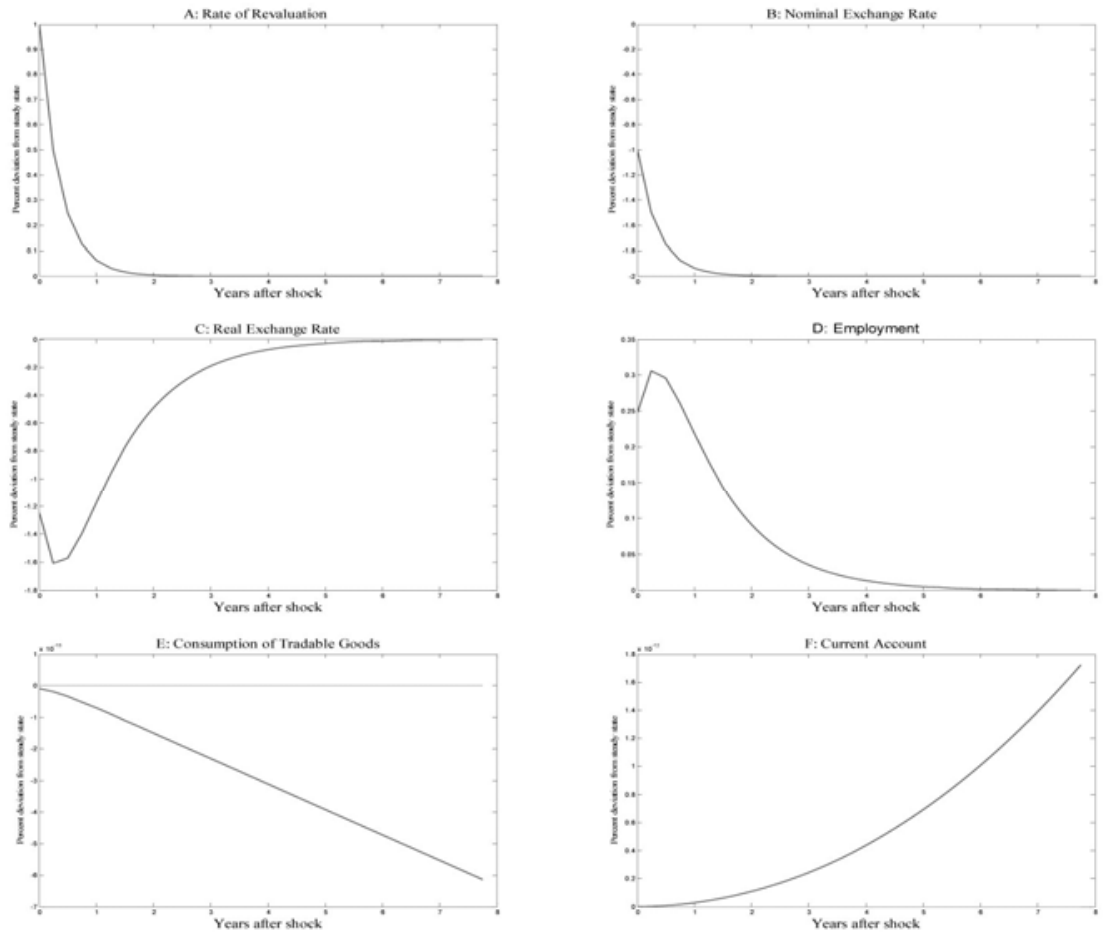

Figure 4. Temporary stabilization: Response of other variables
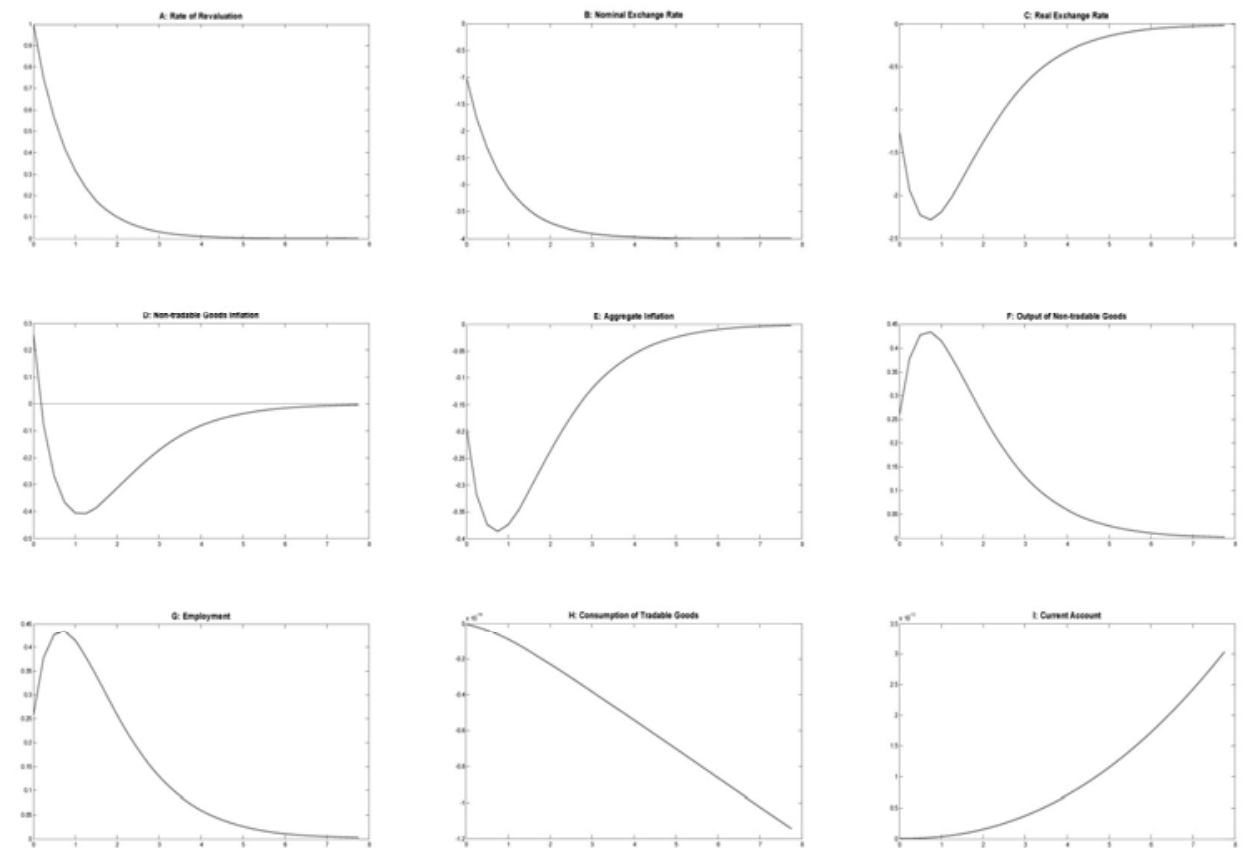

Figure 5. Temporary stabilization: Impulse responses to $1 \%$ revaluation shock with $\phi=0.75$ 

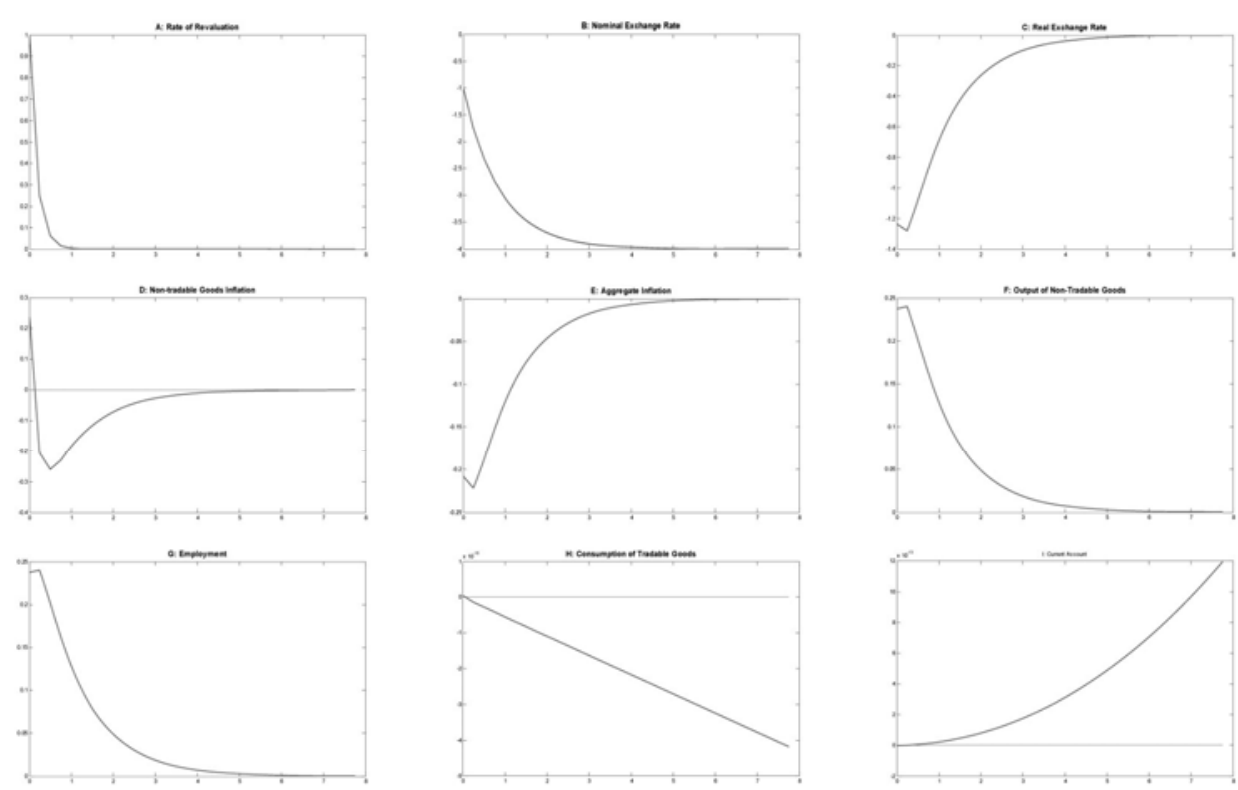

Figure 6. Temporary stabilization: Impulse responses to $1 \%$ revaluation shock with $\phi=0.25$ 